studentship, and Shell Oil of Canada for a maintenance grant.

F. H. C. EDGECOMBE

R. G. W. NORRISH

Department of Physical Chemistry, University of Cambridge.

${ }^{1}$ Gobrecht, H., Ann. Phys., 31, 181 (1938).

2 Filippov, A. N., Larionov, I., and Seidel, A., C.R. Acad. Sci., U.R.S.S., 20, 351 (1938).

${ }^{3}$ Mukherji, P. C., Z. Phys, 109518 (1938).

- Mukherji, P. C., Indian J. Phys., 13, 158 (1939).

${ }^{5}$ Heidt, L. J., Solar Energy Research, edit. by Danlels, F., and Duffe, J. A. (1.955).

' Heidt, L. J., and Smith, M. E., J. Amer. Chem. Soc., 70, 2476 (1956).

'Erhard, K. H. I., and Norrish, R. G. W., Proc. Roy. Soc., A, 234, 178 (1956).

' Feigl, F., Spot Tests, Inorganic Applications, 197 (Elsevier, London, 1956).

- Bacon, R. G. R., Trans. Farad. Soc., 42, 140 (1946).

${ }^{10}$ Saldick, J., J. Polymer Sci., 19, 73 (1956).

11 Weiss, J., and Porrett, D., Nature, 139, 1019 (1937).

\section{Complexes of Ferric Ion with Salicylic Acid and Related Substances}

In connexion with this Unit's interest in the biological actions of salicylic acid and its derivatives ${ }^{1 a}$ and in their physical properties ${ }^{1 b}$, an investigation has been made of the association of the ferric ion with some substituted salicylic acids.

The technique used was a potentiometric one based on that Agren ${ }^{2}$ used in a similar study, the ferric ion concentration being obtained from the value of the oxidationreduction potential and the hydrogen ion concentration from the glass electrode potential. The results obtained from these measurements were analysed by Agren's method and expressed in terms of the constants defined here. Owing to the instability of our glass electrodes in 3 M perchlorate (as used by Agren), all measurements were made at $25^{\circ}$ in solutions brought to an ionic strength of 0.10 by the addition of sodium perchlorate.

The glass electrode was calibrated with standard solutions of perchloric acid. The carboxylic dissociation constants of the acids were determined in separate titrations. Fstimates of the contributions of the hydrolysis products of iron(III) to the oxidation-reduction potential were derived from the work of Milburn and Vosburgh and of Hedström ${ }^{3}$.

Most of the results obtained could be explained in terms of three complexes, $\mathrm{Fe} R_{n}$, where $n=1,2$, or 3 (the parent acid being represented by $R \mathrm{H}_{2}$ ). The complex formation constant for the reaction:

$$
\mathrm{Fe}^{3+}+n R \mathrm{FI}^{-} \rightleftharpoons \mathrm{Fe} R_{n}^{(2 n-3)-}+n \mathrm{H}^{+}
$$

is defined (omitting charges for simplicity) by:

$$
K_{n}=\frac{\left[\mathrm{Fe} R_{n}\right][\mathrm{H}]^{n}}{[\mathrm{Fe}][R \mathrm{H}]^{n}}
$$

Deviations noted at low values of $p H$ and ligand concentration are ascribed to the formation of a protonated complex, $\mathrm{F} \odot \mathrm{RH}^{2+}$, with complex formation constant $K_{1}^{\prime} \mathrm{mM}^{-1}$ :

$$
\mathrm{Fe}^{3+}+R \mathrm{H}^{--} \rightleftharpoons \mathrm{Fe} R \mathrm{H}^{2+} ; K_{1}^{\prime}=\frac{[\mathrm{Fe} R \mathrm{H}]}{[\mathrm{Fe}][R \mathrm{H}]}
$$

The mean values of the complex formation constants obtained are given in Table 1.

Only salicylic acid and $\beta$-resorcylic acid, among the acids examined, appear to have been investigated quantitatively before as regards their complex formation with iron(III). For these acids the results obtained in this work are of a similar order to those of other workers ${ }^{4-8}$; however, there appears to be no previously reported evidence for the protonated complexes $\mathrm{Fe} R \mathrm{HH}^{2+}$.

\begin{tabular}{|c|c|c|c|c|c|}
\hline & $p \cdot \boldsymbol{K}_{\boldsymbol{a}}$ & $K_{1}^{\prime} \mathrm{mM}^{-1 *}$ & $K_{1}$ & $\boldsymbol{K}_{\mathbf{E}}$ & $\boldsymbol{K}_{\mathbf{3}} *$ \\
\hline $\begin{array}{l}\text { Salicylic acid } \\
o \text {-Cresotic acid }\end{array}$ & $\begin{array}{l}2 \cdot 82 \\
2 \cdot 82\end{array}$ & $\begin{array}{l}40 \\
40\end{array}$ & $\begin{array}{l}820 \\
385\end{array}$ & $\begin{array}{l}17 \\
2 \cdot 9\end{array}$ & $\begin{array}{l}7 \times 10^{-5} \\
2 \times 10^{-4}\end{array}$ \\
\hline$m$-Cresotic acid & $2 \cdot 97$ & 40 & 980 & 17 & $2 x^{+}+0$ \\
\hline -Cresotic acid & $2 \cdot 90$ & 30 & 950 & 18 & \\
\hline -isoPropylsalicylic acid & $2 \cdot 76$ & $\dagger$ & 350 & & \\
\hline Methylsalicylic acid & $\overline{3} \cdot 16$ & + & 380 & $4 \cdot 6$ & $1 \times 10^{-3}$ \\
\hline$\gamma$-Resorcylic acid & $1 \cdot 07$ & $\frac{1}{80}$ & 575 & 16 & $-70-4$ \\
\hline$\beta$-Resorcylic acid & & 60 & 1,340 & & $2 \times 10^{-4}$ \\
\hline
\end{tabular}

Table 1. Complex Formation Constants of Some Phenolic Acids with FERRIC ION AT $25^{\circ}$ AND IN A MEDIUM OF IONIC STRENGTH 0.10

* These values are less reliable and are included only to give an indication of order of magnitude.

+ Not measured.

- No complex detected.

To the extent that the structures of the complexes of the substituted salicylic acids are similar, they might have been expected to have had the same stabilities relative to the acid strengths of the phenolic groups, that is, similar values of $K_{n}{ }^{8}$. However, it will be seen that groups in the 4- and 5-positions with electron donor properties increase the value of $K_{1}$ (cf., $m$-cresotic acid, $p$-cresotic acid, and $\beta$-resorcylic acid), and where this tendency is strong, as in $\beta$-resorcylic acid, a considerable increase in $K_{2}$ results. Apparently an increase in the $\pi$-electron density in the chelate ring stabilizes the complex ${ }^{10}$. The effect of substituents in the 3-and 6-positions indicated in Table 1 could be explained in terms of steric inhibition of resonance ${ }^{11}$. In $\gamma$-resorcylic acid an alternative possibility could be a reduction in electron density in the chelate ring through hydrogen bonding between the uncomplexed phenolic group and the carbonyl oxygen.

I thank Dr. C. J. W. Brooks of this Unit and Dr. G. H. Nancollas, of the University of Glasgow, for their help.

$$
\text { M. V. PARK }
$$

Clinical Chemotherapeutic Research Unit, Western Infirmary, Glasgow.

${ }^{2} a$, Andrews, M. M., Brit. J. Pharmacol., 13, 419 (1958); Biochem. J., 75, 298 (1960). Lightbody, T. D., and Reid, J., Brit. Med. J., i, 1704 (1960). b. Brooks. C. J. W., Eglinton, G., and Morman, J. F., J. Chem. soc., 661 (1961).

2 Agren, A., Acta Chem. Scand., 8, 266 (1954).

${ }^{3}$ Milburn, R. M., and Vosburgh, W. C., J. Amer. Chem. Soc., 77, 1352 (1955). Hedstróm, B. O. A., Arkiv Kemi, 6, 1 (1953).

${ }^{4}$ Agren, A., Acta Chem. Scand., 8, 1059 (1953), and references there cited.

${ }^{5}$ Vareille, L., Bull. Soc, chim. France, 1493 (1955).

'Romain, P., and Colleter, J. C., Bull. Soc. chim. France, 858, 867 (1958). 7 Perrin, D. D., Nature, 182, 741 (1958).

${ }^{8}$ Mattoo, B. N., Z. phys. Chem. (Frankfurt), 13, 316 (1957).

- Agren, A., Svensk kem. Tidskr., 68, 189 (1956).

${ }^{10}$ Jones, J. G., Poole, J. B., Tomkinson, J. C., and Williams, R. J. P., (1958).

${ }^{11}$ Irving, H. M., Cabell, M. J., and Mellor, D. H., J. Chem. Soc., 3417 (1953).

\section{Complex Formation between Lead(II) lons and Acetate lons}

THE complex formation between lead(II) and acetate ions has been examined at $25^{\circ} \mathrm{C}$ with $3 \mathrm{M}(\mathrm{Na}) \mathrm{ClO}_{4}$ as the ionic medium. The equilibrium constants were determ. ined by potentiometric titrations at which the free lead concentration, $\left[\mathrm{Pb}^{2+}\right]$, was measured with a lead amalgam electrode and a 'Wilhelm' reference bridge of the type:

\section{$3 \mathrm{M} \mathrm{NaClO}_{4} \mid 2.99 \mathrm{M} \mathrm{NaClO}_{4}+0.01 \mathrm{M} \mathrm{AgClO}_{4}{ }^{\prime} \mathrm{AgCl}, \mathrm{Ag}$}

In each series the analytical lead concentration, $\mathbf{C}_{\mathbf{P b}^{2+} \text {, }}$ was kept constant while the ligand concentration was varied. In order to avoid hydrolysis of the lead ions a suitable amount of perchloric acid was added to the lead perchlorate solutions.

According to the methods of Leden and Fronæus only mononuclear complexes could be found. The species identified were $\mathrm{PbAc}^{+}, \mathrm{PbAc}_{2}, \mathrm{PbAc}_{3}{ }^{-}, \mathrm{PbAc}_{4}{ }^{2-}$, and approximate values of their complex constants, $\beta_{n}=\frac{\left[\mathrm{PbAc}_{n}\left({ }^{n-2}\right)^{-}\right]}{\left[\mathrm{Pb}^{2+}\right]\left[\mathrm{Ac}^{-}\right]^{n}}$, were calculated. These constants were then refined by high-speed computing using $\mathbf{a}$ Ferranti-Mercury computer and the 'Letagrop Vrid' 